\title{
Evaluasi Persepsi Pengguna dalam Penerapan Sistem Informasi Ketersediaan Ruang Rawat dan Ketersediaan Darah di Rumah Sakit Kabupaten Pekalongan
}

\author{
Irnawati $^{1)}$, Mokhammad Arifin ${ }^{2)}$, Halim Indra Kusuma ${ }^{3)}$ \\ ${ }^{1,2)}$ Dosen Prodi Ners STIKES Muhammadiyah Pekajangan Pekalongan \\ 3) Kepala Unit IT STIKES Muhammadiyah Pekajangan Pekalongan
}

\begin{abstract}
Abstrak. Petugas kesehatan sering mengalami kesulitan dalam mencari rumah sakit rujukan dan kantong darah untuk transfusi karena belum tersedianya sistem informasi ruang rawat di rumah sakit dan informasi stok darah PMI yang terintegrasi dan mudah diakses dengan "one click". Adanya solusi dengan aplikasi siDarurat yang merupakan sistem informasi ketersediaan ruang rawat dan ketersediaan darah berbasis website yang dapat diakses melalui personal computer, handphone, dan android.Tujuan :untuk mengevaluasi persepsipengguna dalam penerapan sistem informasi ketersediaan ruang rawat dan ketersediaan darah di rumah sakit kabupaten pekalongan.Metode : Penelitian ini merupakan penelitian kuantitatif dengan rancangan penelitian cross sectional. Sampel yang digunakan sebanyak 42 responden yang merupakan dokter, perawat, bidan, analis baik dirumah sakit maupun puskesmas serta masyarakat.Uji statistik yang digunakan adalah analisis univariat dengan distribusi frekuensi.Hasil : sebagian besar $84 \%$ responden menyatakan tampilan atau user interface dari website sidarurat.com sangat bagus dan penggunaan bahasa mudah difahami, 86\% responden menyatakan informasi tentang kesediaan ruang rawat dan ketersediaan darah dibutuhkan sehari-hari serta mudah diakses dari handphone atau tablet, $80 \%$ responden menyatakan data yang tersaji dalam website sidarurat.com akurat dan sesuai dengan harapan, Kesimpulan: berdasarkan persepsi pengguna website sidarurat.com tampilan sangat bagus, bahasanya mudah difahami, informasinya dibutuhkan sehari-hari, mudah diakses dari handphone dan tablet, serta akurat dan sesuai dengan harapan.
\end{abstract}

\section{Evaluation of The Perception of The User in The Application of Information Systems and Rooming Space Availability Availability of Blood in Hospitals Pekalongan}

Abstrack. Health care professionals often experience in finding reffereal hospital and blood for transfusion due to unavailibility of integrated information system at the ward in the hospital and information of blood stock at Indonesian blood bank which is easily to access with one click. SiDarurat application is an information system of the availibility of bed in the ward and blood with the websites based which can be access through personal computer, handphone, and android. Purpose:to evaluate the perception of the user in the implementation of bed and blood availibility information system at the hospital in pekalongan region. Method: this study is quantitative study with cross sectional approach. 42 respondents were included in this study involving doctors, nurses, midwifes and laboratoriun technicians of the hospitals and publich health community. Univariat analysis with fequency distribution was occupied for statistical examination. Result: 84\% of the respondents explain that the performance or interface user of the website of SiDarurat.com was very good and the language was easy to understand, $86 \%$ of the respondents said that the information of the bed and blood availibility is needed daily and easy to access from mobile phone and tablet, $80 \%$ of the respondents explained the data provided in the sidarurat website was accurate and as what their expected. Conclusion: based on the perception of the sidarurat website users, the sidarurat websites had a very good 
performance, the language was easily to understand, the information is needed daily and easy to access through mobile phone and tablet and accurate and the content as what users expected.

Kata Kunci : evaluation of information system, sidarurat, user perseption

\section{PENDAHULUAN}

Saat ini sulit membayangkan pelayanan kesehatan tanpa Teknologi Informasi dan Komunikasi (TIK). Industri pelayanan kesehatan mengandalkan data dan informasi untuk setiap segi pengirimannya. Besarnya jumlah data yang dihasilkan secara manual (paper based) sebagian besar tidak terstruktur, penggunaannya terbatas dalam mendukung pelayanan kesehatan. TIK memiliki kapasitas untuk mengubah industri kesehatan dan cara untuk memanajemen data, informasi, dan pengetahuan dan merevolusi cara dokter bekerja. Penggunaan teknologi informasi kesehatan menjanjikan dalam meningkatkan efisiensi, efektivitas biaya, kualitas, dan keamanan pemberian perawatan medis dalam sistem kesehatan (Rodrigues, J, 2010).

Setiap orang memiliki risiko jatuh sakit dan membutuhkan biaya cukup besar ketika berobat ke rumah sakit.Apalagi, jika sakit yang dideritanya merupakan penyakit yang kronis atau tergolong berat.Untuk memberikan keringanan biaya, pemerintah mengeluarkan Program JKN (Jaminan Kesehatan Nasional). Program pelayanan kesehatan yang merata dan tidak diskriminatif, diatur dalam Undang-undang Nomor 40 tahun 2004 tentang
Sistem Jaminan Sosial Nasional (SJSN), kemudian

diimplementasikan ke dalam Undang-Undang (UU) Nomor 24 Tahun 2011 tentang Badan Pengelola Jaminan Sosial (BPJS) (Kemenkes, 2013).

Sistem rujukan adalah suatu sistem penyelenggaraan kesehatan yang melaksanakan pelimpahan tanggung jawab yang timbal balik terhadap satu kasus penyakit atau masalah kesehatan secara vertikal dalam arti dari unit yang berkemampuan kurang kepada unit yang lebih mampu atau secara horizontal dalam arti unit-unit yangsetingkat

kemampuannya. Sistem rujukan mengatur alur dari mana dan harus ke mana seseorang yang mempunyai masalah kesehatan tertentu untuk memeriksakan masalah kesehatannya (Kemenkes, 2013).

Sistem ini diharapkan semua memperoleh keuntungan. Misalnya, pemerintah sebagai penentu kebijakan kesehatan (policy maker), manfaat yang akan diperoleh di antaranya, membantu penghematan dana dan memperjelas sistem pelayanan kesehatan. Bagi masyarakat sebagai pemakai jasa pelayanan akan meringankan biaya pengobatan karena pelayanan yang diperoleh sangat mudah. Bagi 
pelayanan kesehatan (health
provider), mendorong jenjang karier
tenaga kesehatan, selain
meningkatkan pengetahuan
maupun keterampilan, serta
meringankan beban tugas (Kemenkes, 2013).

Sistem rujukan pelayanan kesehatan dilaksanakan secara berjenjang sesuai dengan kebutuhan medis. Pada pelayanan kesehatan tingkat pertama, peserta dapat berobat ke fasilitas kesehatan primer seperti puskesmas, klinik, atau dokter keluarga yang tercantum pada kartu peserta BPJS Kesehatan. Apabila peserta memerlukan pelayanan lanjutan oleh dokter spesialis, maka peserta dapat dirujuk ke fasilitas kesehatan tingkat kedua atau fasilitas kesehatan sekunder. Pelayanan kesehatan di tingkat ini hanya bisa diberikan jika peserta mendapat rujukan dari fasilitas primer.Rujukan ini hanya diberikan jika pasien membutuhkan pelayanan kesehatan spesialistik dan fasilitas kesehatan primer yang ditunjuk untuk melayani peserta, tidak dapat memberikan pelayanan kesehatan sesuai dengan kebutuhan peserta karena keterbatasan fasilitas, pelayanan, dan atau ketenagaan. Jika penyakit peserta masih belum dapat tertangani di fasilitas kesehatan sekunder, maka peserta dapat dirujuk ke fasilitas kesehatan tersier. Di sini, peserta akan mendapatkan penanganan dari dokter sub-spesialis yang menggunakan pengetahuan dan teknologi kesehatan subspesialiastik (Kemenkes, 2016).

Peserta JKN harus mengikuti sistem rujukan yang ada. Sakit apa pun, kecuali dalam keadaan darurat, harus berobat ke fasilitas kesehatan primer, tidak boleh langsung ke rumah sakit atau dokter spesialis. Jika ini dilanggar peserta harus bayar sendiri (Kemenkes, 2013).

Namun realitas di lapangan tak semudah membalikkan telapak tangan.Perpindahan jaminan kesehatan ini banyak mengalami kendala.Sistem rujukan pasien dirasakan masih tidak efektif dan efisien, masih banyak masyarakat belum mendapat menjangkau pelayanan kesehatan, akibatnya terjadi penumpukan pasien yang luar biasa di rumah sakit besar tertentu.Pemahaman masyarakat tentang alur rujukan sangat rendah sehingga mereka tidak mendapatkan pelayanan sebagaimana mestinya.Pasien menganggap sistem rujukan birokrasinya cukup rumit, sehingga pasien langsung merujuk dirinya sendiri untuk mendapatkan kesehatan tingkat kedua atau ketiga (Kemenkes, 2013).

Keluhan lain terkait sistem rujukan BPJS yang dirasakan adalah ketidaksiapan tenaga kesehatan dan kurangnya fasilitas di layanan kesehatan primer, kasus yang seharusnya dapat ditangani di layanan primer atau sekunder tetapi langsung dirujuk ke rumah sakit tersier. Lain halnya dengan keluhan PNS di mana jika rujukan harus melalui 
puskesmas sementara mereka harus bekerja lamanya proses pengurusan tersebut menghabiskan jam kerja para PNS. Sistem rujukan seharusnya tidak membuat PNS kesulitan.Idealnya rujukan tidak hanya berasal dari Puskesmas, namun juga layanan primer lain, misalnya klinik tempat pekerja tersebut (Kemenkes, 2013).

Tidak hanya masyarakat pengguna saja yang mempunyai masalah dalam sistem rujukan ini, petugas kesehatan dai level PPK 1 dilapangan juga mempunyai masalah yang kadang tidak diaketahui dan dipahami oleh masyarakat pengguna, masalah masalah tersebut antara lain : Sulitnya mencari rumah sakit rujukan, belum tersedianya sistem informasi ruang rawat di rumah yang terintegrasi jarak ketempat rujukan, medan ketempat tujuan serta sarana transportasi ketempat tujuan (Kemenkes, 2013).

Permasalahan pertamamerupakan masalah yang terjadi sebagai meningkatnya kesadaran masyarakat yaitu ketersedian ruang rawat karena banyaknya pengguna fasilitas BPJS ini, masih ada pemahaman dalam proses rujukan yang berlaku di BPJS dari PPK 1, PPK 2, dan PPK3 sehingga masing sering terjadi peserta "Nyelonong" ke PPK 2 tanpa pengantar dari PPK 1 dan menimbulkan konflik di anatara peserta BPJS dengan Penyedia layanannya (Kemenkes, 2013).
Berdasarkan hasil studi pendahuluan ditemukan permasalahan kedua adalah masalah spesifik bagi petugas kesehatan dilapangan yang bekerja 24 jam, ketika harus merujuk pasien seringkali sulit mendapat info cepat dimana rumah sakit yang tersedia ruang rawat tanpa harus menghubungi satu-persatu rumah sakit. Beberapa kasus terjadi terjadi bahkan sampai terjadi merujuk ke luar wilayah Kabupaten Pekalongan karenasulitnyamengaksesinformasi ini. Beberapa faktor penyebab masalah ini antara lain adalah "diperoleh informasi" ruang rawat yang akurat namun rumah sakit sudah penuh atau "tidak diperoleh infomasi" yang akurat karena telepon sibuk, jaringan yang tergangu dan lain-lain.

Selain informasi tentang ketersediaan ruang rawat, informasi tentang ketersediaan darah juga merupakan hal yang sangat penting pada kodisi kegawatdaruratan khususnya pada kasus kasus kehilangan darah seperti kecelakaan lalu lintas, perdarahan post partum, opersi besar, keganasanan dan lain-lain.

Dukungan sarana komunikasi dan telekomunikasi diIndonesia sudah cukup baik dengan tersedianya jaringan CDMA, GSM, 2G, 3G dan terakhir 4G. Juga kepemilikan Telepon Gadget dan Smartphone bukanlah yang sulit dimiliki bagi siapa saja salah satunya petugas kesehatan dan masyarakat, apalagi di Kabupaten Pekalongan yang 
hampir semua daerah dijangkau provider telekomunikasi.

\section{METODE PENELITIAN}

Penelitian ini merupakan penelitian kuantitatif dengan rancangan penelitian cross sectional(Notoadmodjo, 2005).

Tehnik pengambilan sampel pada penelitian ini menggunakan Purposive Samplingadalah cara pengambilan sampel didasarkan pada suatu pertimbangan tertentu yang di buat oleh peneliti sendiri, ciri atau sifat-sifat populasi yang sudah diketahui sebelumnya (Notoadmodjo, 2005).

Penelitian ini dilakukan Kabupaten Pekalongan dan Pengambilan data penelitian dilakukan pada tanggal 1 20 Agustus 2016.

\section{HASIL PENELITIAN}

1. Karakteristik Responden

KarakteristikRespondenBerdasark an User siDARURAT di

Kabupaten Pekalongan

\begin{tabular}{|c|c|c|c|}
\hline No. & User & Frekuensi & $\begin{array}{c}\text { Prosentase } \\
(\%)\end{array}$ \\
\hline 1. & $\begin{array}{l}\text { Dinas } \\
\text { kesehatan }\end{array}$ & 6 & 5,2 \\
\hline 2. & $\begin{array}{l}\text { Rumah } \\
\text { sakit }\end{array}$ & 32 & 27,6 \\
\hline 3. & Puskesmas & 39 & 33,6 \\
\hline 4. & $\begin{array}{l}\text { Balai } \\
\text { pengobatan }\end{array}$ & 2 & 1,7 \\
\hline 5. & $\begin{array}{l}\text { Sekolah } \\
\text { dasar }\end{array}$ & 1 & 0.91. \\
\hline 6. & $\begin{array}{l}\text { Sekolah } \\
\text { Menengah } \\
\text { Atas }\end{array}$ & 1 & 0,9 \\
\hline 7. & $\begin{array}{l}\text { Perguruan } \\
\text { Tinggi }\end{array}$ & 2 & 1,7 \\
\hline
\end{tabular}

\begin{tabular}{clcc}
\hline 8. & Masyarakat & 3 & 2,6 \\
\hline 9. & Mahasiswa & 30 & 25,8 \\
\hline
\end{tabular}

2. Gambaran Persepsi Pengguna dalam Penerapan Sistem Informasi Ketersediaan Ruang Rawat dan Ketersediaan Darah di Rumah Sakit Kabupaten Pekalongan

\begin{tabular}{|c|c|c|}
\hline No & Pertanyaan & Skor \\
\hline 1 & $\begin{array}{l}\text { Tampilan website } \\
\text { sidarurat.com sudah } \\
\text { bagus }\end{array}$ & 4,2 \\
\hline 2 & $\begin{array}{l}\text { Penggunaan bahasa } \\
\text { dalam website } \\
\text { sidarurat.com } \\
\text { mudah dipahami }\end{array}$ & 4,2 \\
\hline 3 & $\begin{array}{l}\text { Informasi yang } \\
\text { diberikan webiste } \\
\text { sidarurat.com } \\
\text { dibutuhkan sehari- } \\
\text { hari }\end{array}$ & 4,3 \\
\hline 4 & $\begin{array}{l}\text { Data yang tersaji } \\
\text { dalam website } \\
\text { sidarurat.com } \\
\text { akurat, dan sesuai } \\
\text { dengan harapan }\end{array}$ & 4,0 \\
\hline 5 & $\begin{array}{l}\text { Website } \\
\text { sidarurat.com } \\
\text { mudah diakses dari } \\
\text { handphone/tablet }\end{array}$ & 4,3 \\
\hline
\end{tabular}

PEMBAHASAN

Pengguna dalam

Penerapan Sistem Informasi

Ketersediaan Ruang Rawat dan

Ketersediaan Darah di Rumah Sakit

Kabupaten Pekalongan 
\begin{tabular}{lrrr} 
Hasil pengujian & dari & sistem \\
berdasarkan & uji & UAT & (User \\
Acceptance & Test) & yang & telah \\
dilakukan & oleh & \multicolumn{2}{c}{ pengguna }
\end{tabular} menunjukan bahwa sebagian besar yaitu $84 \%$ responden menyatakan tampilan atau user interface dari website sidarurat.com sangat bagus. Tampilan erat kaitannya dengan mata atau penglihatan jadi tampilan harus bagus atau eye catching agar tidak menimbulkan kejenuhan. Tampilan website sidarurat.com mudah digunakan dan ringan sehingga tidak membebani kinerja komputer atau handphone atau tablet. Tampilan website sidarurat.com sangat fleksibel jadi bisa di instal diberbagai tipe komputer atau handphone atau tablet (Abdelhak, 2007).

Hasil pengujian dari sistem berdasarkan uji UAT (User Acceptance Test) yang telah dilakukan oleh pengguna menunjukan bahwa sebagian besar yaitu $84 \%$ responden menyatakan penggunaan bahasa dalam website sidarurat.com mudah dipahami. Website sidarurat.com mudah digunakan juga karena tampilannya menggunakan bahasa Indonesia. Bahasa sering digunakan sebagai alat komunikasi untuk menyesuaikan situasi atau kondisi agar dapat disampaikan dan dimengerti oleh lawan bicara, baik dari laras bahasa maupun kata-kata yang digunakan harus disesuaikan dengan lawan bicara agar mudah dipahami (Al-Adaileh, R, 2009).
Hasil pengujian dari sistem berdasarkan uji UAT (User Acceptance Test) yang telah dilakukan oleh pengguna menunjukan bahwa sebagian besar yaitu $86 \%$ responden menyatakan informasi tentang ketersediaan ruang rawat dan ketersediaan darah dibutuhkan sehari-hari. User dari aplikasi ini terdiri dari tenaga kesehatan seperti dokter, perawat, bidan dan tenaga kesehatan lainnya dan juga masyarakat. Bagi tenaga kesehatan khusunya di Puskesmas yang bekerja 24 jam, ketika harus merujuk pasien seringkali sulit mendapat info cepat dimana rumah sakit yang tersedia ruang rawat tanpa harus menghubungi satu persatu rumah sakit. Beberapa kasus terjadi bahkan harus merujuk ke luar wilayah Kabupaten Pekalongan karena sulitnya mengakses informasi mengenai ketersediaan ruang rawat.

Beberapa faktor penyebab masalah ini adalah "diperoleh informasi" ruang rawat yang akurat namun rumah sakit sudah penuh atau "tidak diperoleh informasi" yang akurat karena telepon sibuk, jaringan yang terganggu, dan lainlain. Pada kondisi yang mendesak misalnya gagal jantung, gagal nafas, perdarahan post partum, eklamsia atau kondisi yang mengancam nyawa lainnya petugas sangat ingin segera mendapat informasi rumah sakit yang bisa digunakan untuk merujuk dan hal itu bisa menghabiskan waktu 1 jam 
hanya untuk mendapat informasi akurat karena harus menghubungi rumah sakit secara manual. Hal inipun tergantung situasi dan kondisi dan apabila terjadi pasien akan menunggu lama untuk sampai di tempat tujuan apalagi dengan kondisi yang mengancam nyawa tentu akan menimbulkan kekhawatiran tersendiri baik bagi petugas kesehatan maupun keluarganya. Selain informasi tentang ketersediaan ruang rawat, informasi tentang ketersediaan darah juga merupakan hal yang sangat penting pada kondisi kegawatdaruratan khususnya pada kasus-kasus kehilangan darah seperti kecelakaan lalu lintas, perdarahan post partum, operasi besar, keganasan dan lain-lain. Kebutuhan akan darah tidak mengenal waktu, 24 jam sehari bahkan dikala liburpun harus disiagakan, sehingga informasi terbuka akan ketersediaan darah menjadi sangat penting. Sehingga website sidarurat.com ini sangat dibutuhkan oleh tenaga kesehatan dengan "one click" dapat mendapatkan informasi yang cepat dan akurat terkait ketersediaan ruang rawat dan ketersediaan darah di Kabupaten Pekalongan sehingga dapat mempercepat penanganan pasien dengan kondisi yang mengancam nyawa. Selain tenaga kesehatan, masyarakatpun dapat menggunakan website sidarurat.com ini (Al-Adaileh, R, 2008).

Hasil pengujian dari sistem berdasarkan uji UAT (User
Acceptance Test) yang telah dilakukan oleh pengguna menunjukan bahwa sebagian besar yaitu $80 \%$ responden menyatakan data yang tersaji dalam website sidarurat.com akurat dan sesuai dengan harapan. Peneliti bekerja sama dengan ketua IT di setiap rumah sakit maupun ketua Unit Donor Darah untuk selalu mengupdate data ketersediaan ruang rawat dan ketersediaan darah. Website sidarurat.com juga menyediakan fitur untuk menambah operator, sehingga operator untuk pengupdatean data juga tersebar diruang-ruang rawat inap dan unit donor darah yang bertugas mengupdate data ketersediaan ruang rawat dan ketersediaan darah setiap kali mengalami perubahan (real time) (Abdelhak, dkk, 2007).

Hasil pengujian dari sistem berdasarkan uji UAT (User Acceptance Test) yang telah dilakukan oleh pengguna menunjukan bahwa sebagian besar yaitu $86 \%$ responden menyatakan website sidarurat.com mudah diakses dari handphone/tablet. Saat ini handphone/tablet telah mampu mengubah ketergantungan akan komputer dekstop, bukan hanya dalam hal teknologinya namun kemudahan mobilitasnya yang tinggi yang bisa menarik minat penggunanya. Dilihat dari segi dimensi perangkat tentunya orang akan lebih memilih handphone yang hanya segenggaman tangan daripada harus menjinjing $\mathrm{PC}$ atau laptop yang berat. Untuk 
melakukan tugas atau aktifitas memang lebih menguntungkan handphone daripada PC. Dilihat dari segi mobilitas dan kebutuhan sehari-hari penggunanya tentu handphone lebih mudah digunakan dan sangat user friendly di mata user. Sehingga baik tenaga kesehatan maupun masyarakat bisa mendapatkan informasi mengenai ketersediaan ruang rawat dan ketersediaan darah kapanpun dan dimanapun berada dengan menggunakan handphone/tablet (Rotrigeus, J, 2010).

\section{KESIMPULAN}

1. Sebagian besar yaitu $84 \%$ responden menyatakan tampilan atau user interface dari website sidarurat.com sangat bagus.

2. Sebagian besar yaitu $84 \%$ responden menyatakan penggunaan bahasa dalam website sidarurat.com mudah dipahami.

3. Sebagian besar yaitu $86 \%$ responden menyatakan informasi tentang ketersediaan ruang rawat dan ketersediaan darah dibutuhkan sehari-hari.

4. Sebagian besar yaitu $80 \%$ responden menyatakan data yang tersaji dalam website sidarurat.com akurat dan sesuai dengan harapan.

5. Sebagian besar yaitu $86 \%$ responden menyatakan website sidarurat.com mudah diakses dari handphone/tablet.

\section{SARAN}

1. Bagi Pemerintah Kabupaten Pekalongan
Membuat kebijakan khusus dari Dinas Kesehatan karena diperlukan transparansi masingmasing rumah sakit yang ada di Kabupaten Pekalongan karena memerlukan update data setiap terjadi perubahan data ruang rawat selama 24 jam dan ketersediaan darah demi keberlangsungan website sidarurat.com ini. Bila sistem di Kabupaten Pekalongan berhasil maka dapat dikembangkan di Kota Pekalongan, Batang, dan Pemalang sebagai daerah alternatif rujukan. Informasi yang tersedia dalam website sidarurat.com ini juga dapat dijadikan bahan pembuat keputusan oleh Dinas Kesehatan.

2. Bagi rumah sakit

Membuat kebijakan khusus dari rumah sakit agar masing-masing operator update data setiap terjadi perubahan data ruang rawat dan data ketersediaan darah selama 24 jam demi keberlangsungan website sidarurat.com ini. Rumah sakit juga dapat me link kan program ini ke program yang ada di rumah sakit jika tersedia. Informasi yang tersedia dalam website sidarurat.com ini juga dapat dijadikan bahan pembuat keputusan oleh Direktur Rumah Sakit.

3. Bagi PMI

Membuat kebijakan khusus dari PMI agar masing-masing operator dapat mengupdate data setiap terjadi perubahan data ketersediaan darah selama 24 jam demi keberlangsungan website sidarurat.com iniInformasi yang 
tersedia dalam website sidarurat.com ini juga dapat dijadikan bahan pembuat keputusan oleh Ketua Unit Donor Darah.

4. Bagi Institusi Pendidikan

Penelitian ini dapat dijadikan bahan untuk mengembangkan penelitian yang lain yang bermanfaat.

5. Bagi masyarakat

Dapat menggunakan website sidarurat.com karena dapat memberikan informasi yang akurat tentang ketersediaan ruang rawat dan ketersediaan darah sehingga dapat segera mendapatkan pertolongan dari tenaga kesehatan.

6. Bagi peneliti lain

Mengembangkan penelitian ini dengan menambah variabel dan menggunakan analisa bivariat atau multivariat.

\section{DAFTAR PUSTAKA}

Abdelhak, M, Grostick, S, Hanken, M, Jacobs, E. 2007. Health Information Management of a Strategic Resource, Third edition. Saunders Elsevier; USA.Bowers, Maggie. (2004). Magic(al) Realism. London: Routledge

Al-adaileh. R. 2008. Essentials of Management Information Systems. Karak- Jordan. Yazeed Publications.

Al-adaileh, R. 2009. An Evaluation of Information Systems Success: A User Perspective- the Case of jordan Telecom

Group. European Journal of Scientific Research Vol. 37 No.2 (2009) pp. 226-239. Karak- Jordan. EuroJournals Publishing, Inc.

Kementrian Kesehatan Republik Indonesia. 2013. Buku Pegangan Sosialisasi Jaminan Kesehatan Nasional (JKN) dalam Sistem Jaminan Sosial Nasional KEMENKES RI: Jakarta.

Kementrian Kesehatan Republik Indonesia. 2016. Buku Saku FAQ (Frequently Asked Questions) BPJS Kesehatan. KEMENKES RI: Jakarta.

Notoatmodjo, Soekidjo. 2005.Ilmu

Kesehatan Masyarakat (Prinsip-Prinsip Dasar). PT. Rineka Cipta: Jakarta.

Rodrigeus, Joel. 2010. Health Information Systems: Concepts, Methodologies, Tools, and Aplications. Volume I. New York. Medical Information Science Reference. 
Jurnal Ilmiah Kesehatan (JIK) Vol X, No 2, September 2017 ISSN 1978-3167 